DOI: $10.36315 / 2019$ inpact006

Psychological Applications and Trends 2019

\title{
THE EFFECTS OF CIVIC PARTICIPATION ON JAPANESE OLDER ADULTS
}

\author{
Keiko Katagiri \\ Graduate School of Human Development / Kobe Active Aging Research Hub, Kobe University (Japan)
}

\begin{abstract}
The growing elderly population in Japan has invited many social problems, one such problem being a shortage of productive population members to support the large elderly dependent population. Another is the seniors themselves; normative roles for seniors after retirement do not exist. In 2013, the Japanese government amended the Elderly Persons Employment Stabilization Law, which requires companies to provide jobs to employees until the age of 65 . However, most Japanese companies have a mandatory retirement age of 60 , and once senior workers reach this age, the companies prepare new labour contracts under which they work at lower rates and no designation. Following this amendment, an increased number of workers in their 60s have joined the workforce. Work is one means for seniors to engage in society; however, it cannot be a source of self-esteem, as this changes after the age of 60, when retirement become mandatory. Katagiri proposed a model of civic participation for seniors; this model delineates three options: social participation, productive activity, and civic engagement. The purpose of this study was to explore the effect of working condition and social participation on health. We used data from a nationally representative sample of the 2012 Japanese General Social Survey. The responses of participants aged 60 to 74 years were analysed. Of these, $18.1 \%$ of respondents were full-time workers and $17.5 \%$ were part-time workers, while $66.4 \%$ did not work. We found that $32.5 \%$ people did not participate in any activities. About half the full-time and part-time workers did not engage in any non-work-related activities. We conducted an ANCOVA to compare mental health among individuals working under different conditions and engaging in non-work-related activities, controlling for subjective health and education. The results showed a main effect of participation in non-work-related activities for the male respondents. The male respondents engaging in social or civic activities showed better mental health than those not engaging in any activities, regardless of work status. For the female respondents, in addition to the same positive effect of participation, the respondents working part-time showed better mental health than those working full-time or not working. The effect of participation was similar to that seen in the male respondents. These results suggest that the meaning of work may differ for older workers. Work cannot be a source of self-esteem, and workers need meaningful activities to find meaning in life.
\end{abstract}

Keywords: Older workers, social participation, work life balance, civic engagement, meaning in life.

\section{Introduction}

\subsection{Increase of older workers in Japan}

The aging rate of the Japanese population has been increasing; it reached $27.7 \%$ in 2018 and is estimated to reach $33.3 \%$ in 2036 and $38.4 \%$ in 2065 . In tandem, the productive population has been decreasing. The implication of this for the younger generation is heavy burden in terms of social security costs. In the worst-case scenario, a ratio of one young person supporting one old person has been estimated. Such a state of affairs cannot be deemed sustainable.

The Japanese government is struggling to solve this problem by encouraging the elderly to remain a part of the work force as long as possible and to this effect revised the "Law Concerning Stabilization of Employment of Older Persons." Until recently, the mandatory retirement age in Japan was 60; however, the revision of the law obligated companies to retain their employees until the age of 65 . Note that this does not mean that the retirement age has been extended from 60 to 65. Most companies continue to set the retirement age as 60, which means that the existing labour contract ends once the employee has turned 60 , and a new contract begins. This new contract is usually completely different; this is a significant reduction in salary, sometimes one third of the original. In addition, the employee serves as a member of staff, with no designation. The work hours remain the same: Monday to Friday, from 9 a.m. to 5 p.m. This means that seniors have to work under rather devalued conditions. Despite this, most choose to continue working for 
financial reasons. The annuity sum is estimated to decrease with the increase in the older population. At present, they have to support not only their older parents but also sometimes their adult children, who are still dependent on them after graduation from university. Furthermore, the extended life expectancy make it impossible for them to estimate how much they will need to save for retirement.

To add a different perspective, the devalued working conditions after the retirement age of 60 cannot serve as a source of self-esteem. Katagiri (2012) investigated the effect of work status and social participation on seniors in their 60s. Social participation was found to have a positive effect on self-esteem. Working men who engaged in a social activity were found to have higher self-esteem than those who did not engage in any social activity. She interpreted these results in light of the devalued working conditions for older workers.

One more aspect to be considered is work hours and days. Most older workers would rather not work the same hours as they did before; they prefer fewer hours a day or fewer days a week. A few studies have investigated differences in working conditions based on work hours. Corna (2016) compared changes in work and health status by gender using longitudinal data from Americans ranging from 52 to 69 years. Working condition was divided into full-time, part-time, and retired. Men were found to be in the best of health when they switched from full-time to part-time job in their mid-sixties, whereas for women, the same was true for those who continued part-time work from the ages of 52 to 69. This shows that working condition affects health status. However, to date no studies considering work status have been conducted in Japan.

\subsection{Purpose}

Katagiri (2017) proposed a model of civic participation for seniors; this model delineates three options for seniors: social participation, productive activity, and civic engagement. Social participation includes group activity, hobbies, sports, and lifelong learning etc. Productive activity includes paid or unpaid work. Civic engagement means engaging in civic or political activities. The first purpose of this study was to explore the effect of work (productive activity) and social activity (social or civic activity) on health; the second was to observe gender differences, if any.

\section{Method}

\subsection{Data}

We conducted a secondary analysis using data from the Japanese General Social Survey 2012, a nationally representative sample of Japan. A sub sample comprised participants in the age group of 60 to 74 years $(\mathrm{N}=1,929)$.

\subsection{Independent variables}

We created three kinds of working conditions - full-time workers, part-time workers, and not working - according to work hours. Full-time workers worked more than 40 hours a day, part-time workers less than 40 hours, and participants with 0 work hours were considered as not working.

We created a dummy variable for social or civic activities other than work. The basis was whether the participants engaged in at least one of the following group activities: political associations, residential/neighbourhood associations, and social service clubs (volunteer group/NPO9, citizens' movement/ consumers' cooperative groups, religious groups, alumni associations, recreational associations (hobbies and sports), labour unions, occupational/professional association/trade unions, etc.).

\subsection{Dependent variables}

Three items measuring mental health were taken from SF 36: "Have you felt calm and peaceful?" "Did you have a lot of energy?" and "Have you felt downhearted and blue? (reversed)?". Answers ranged from "1: None of the time," "2: Little of the time," "3: Some of the time," "4: Most of the time," and "5: All of the time," to organized, as higher scores indicated better mental health. As Cronbach's $\alpha$ was .64, we summed up the scores to determine each participant's mental health score.

\section{Results}

\subsection{Description of the participants}

Table 1 and Table 2 list the characteristics of the participants, who ranged in age from 60 to 89 and were on average healthy and from middle class backgrounds. 
Table 1. Descriptive statistics of participants.

\begin{tabular}{lrr}
\hline & $\mathrm{N}=1,929$ \\
& Mean & $S D$ \\
\hline Age & 70.1 & 7.27 \\
Subjective health (1: Very bad - 5: Very good) & 3.6 & 1.15 \\
Mental health (3-15) & 10.58 & 2.24 \\
Household income (1: Far below average - 5: Far above average) & 2.5 & 0.90 \\
Level of urbanization (1: rural - 5: urban) & 3.2 & 0.92 \\
\hline
\end{tabular}

Table 2. Distribution by demographic characteristics.

\begin{tabular}{llrr}
\hline & & $N$ & $\%$ \\
\hline \multirow{2}{*}{ Gender } & Male & 888 & 0.459865 \\
& Female & 1043 & 0.540135 \\
\hline \multirow{2}{*}{ Education } & Less than high school & 601 & 0.313 \\
& High school & 915 & 0.476 \\
& $1 \mathrm{z}$ & 405 & 0.211 \\
\hline \multirow{2}{*}{ Marital status } & Married & 1427 & 0.74 \\
& Not married & 502 & 0.26 \\
\hline \multirow{2}{*}{ Work status } & Full-time & 289 & 0.154 \\
& Part-time & 351 & 0.187 \\
& Not working & 1238 & 0.659 \\
\hline
\end{tabular}

\subsection{Mental health status by gender, work status, and age group}

Table 3 shows the mental health scores by gender, work status, and age group. First, we observed no statistical differences between men and women. Second, mental health differed based on work status. People working part-time showed better scores than the other two groups. Third, though we observed no differences among age groups, male respondents showed their peak of good mental health in their early $70 \mathrm{~s}$, while female respondents showed their peak in their late $60 \mathrm{~s}$.

Table 3. Mental health by gender, work status, and age group.

\begin{tabular}{clcc}
\hline & & $M$ & $S D$ \\
\hline \multirow{2}{*}{ Gender } & Men & 10.64 & 2.23 \\
& Women & 10.54 & 2.26 \\
\hline \multirow{3}{*}{ Work status } & Full-time & 10.61 & 2.32 \\
& Part-time & 10.90 & 2.18 \\
& Not working & 10.48 & 2.25 \\
\hline \multirow{3}{*}{ Age group } & $60-64$ & 10.52 & 2.15 \\
& $65-69$ & 10.67 & 2.11 \\
& $70-74$ & 10.79 & 2.30 \\
& $75-$ & 10.44 & 2.39 \\
\hline
\end{tabular}

\subsection{Results of the ANCOVA}

We conducted an ANCOVA to compare mental health by gender among individuals in different working conditions and engaging in activities other than work, controlling for subjective health and education.

Subjective health, educational status, and active engagement in social activity showed significant main effects for both men and women. We observed no statistical differences in work status among men. 
On the contrary, for women, subjective health, educational status, active engagement in social activity, and work status showed statistical differences (Figure 1). Women working part-time showed better mental health than those working full-time or not working.

Figure 1. Results of the ANCOVA.
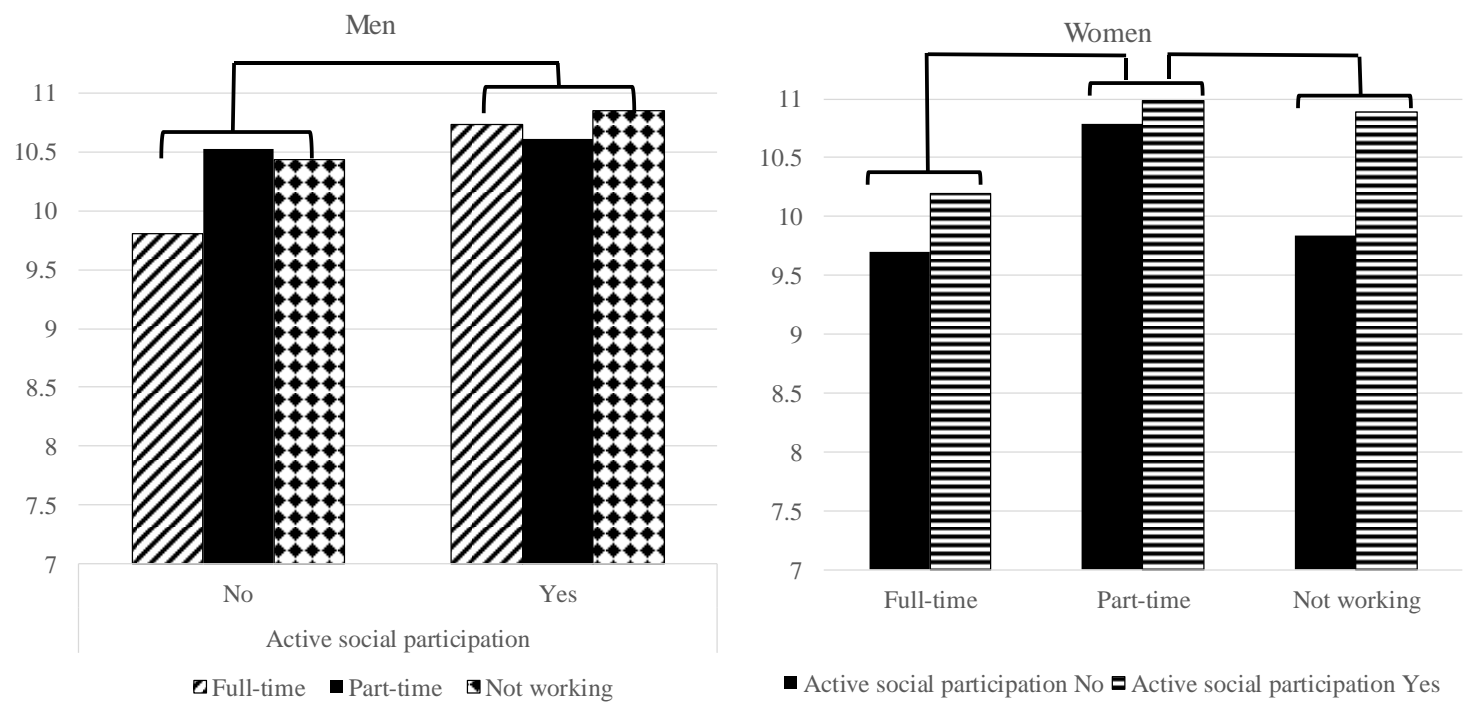

\section{Discussion}

The results show the robust positive effects of active social participation on mental health in both men and women; however, the same was not seen with working conditions. This suggests that men cannot find meaning in work after retirement. Thus, we observed no differences in mental health scores among the male respondents with regard to working conditions. Instead, men were found to have better mental health when they could find a role, network, or passion when engaging in social or civic activities. Conversely, men who could not find a substitute for work tended to feel depressed.

The working conditions of the female respondents were found to affect mental health. Women with part-time jobs were found to have the best mental health. When working full-time, women might have to play multiple roles: wife, mother, caregiver to old parents, and caregiver to grandchildren and this multiple role strain might cause them a great amount of stress (Marks, 1977). However, fewer such roles do not necessarily indicate less stress for middle-aged and old-aged women. Wives with retired husbands sometimes suffer from "homebound husband stress syndrome" and get depressed on account of their husbands staying home all day and not participating in domestic chores (Kurokawa, 2009). If such women are also not working, their retired husbands might be a source of stress.

This study also showed the robust strong positive effects of active social or civic activities. In Japan, the social engagement rate needs to be considered carefully as activeness ranges from merely having a membership in a group activity to active engagement in said activity (Katagiri \& Kim, 2018). Just having a membership alone does not contribute to better mental health; active engagement is the key.

There seem to be two levels of hurdles for Japanese seniors. The first is finding a good group in which to participate. The second is active engagement. Most men spent workaholic lives, devoting very little time to community activities and hobbies. It is therefore difficult for them find even one activity that interests them, and even when they do find one, it is not easy to adapt to a group activity. Sometimes, it may be not easy to get along with other group members, and sometimes they may not find the activity interesting or meaningful enough.

The Japanese government has been promoting the prolonged work life policy, one of the reasons being that work is assumed to have positive effects on health. While some studies do report the positive effects of work on health among seniors (e.g. Ilmarinen, 2001), the results of this study do not support this claim. Regardless of the results, we cannot conclude that working conditions do not matter for older adults, as the working conditions and health status of older workers are dramatically changing. Further investigation of both working conditions and health is needed.

At the same time, the results indicate the importance of work-life balance for older adults. Measures to improve working conditions and encourage active engagement in social or civic activities other than work must be considered. 


\section{References}

Corna, L. (2016). Later-life employment trajectories and health: Evidence from the US. Paper presented at the 45th Annual Conference of the British Society of Gerontology, Stirling, Scotland, P.121.

Ilmarinen, J. E. (2001). Aging workers. Occupational and Environmental medicine, 58(8), 546-546.

Katagiri, K. (2012). Japanese retirees and social participation: A challenge to the third age. Tokyo: University of Tokyo Press. (in Japanese)

Katagiri, K. (2017). Development among third age in super aging society. Tokyo: University of Tokyo Press. (in Japanese).

Katagiri, K., \& Kim, J. H. (2018). Factors determining the social participation of older adults: a comparison between Japan and Korea using EASS 2012. PloS One, 13(4), e0194703.

Marks, S. R. (1977). Multiple roles and role strain: Some notes on human energy, time and commitment. American Sociological Review, 42(6), 921-936.

Nobuo Kurokawa (2009). Homebound husband stress syndrome. Japanese Society of Psychosomatic Medicine, 49(2), 99. 